\title{
Application of prognostic score IPSET-thrombosis in patients with essential thrombocythemia of a Brazilian public service
}

\author{
Patricia Weinschenker Bollmann 5

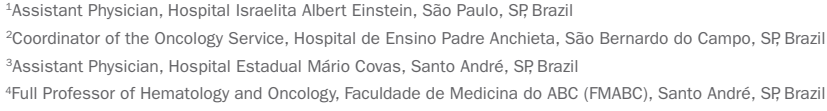

luana Magalhães Navarro ${ }^{1}$, Damila Cristina Trufelli2*, Debora Rodrigues Bonito ${ }^{3}$, Auro del Giglio ${ }^{4}$,

Study conducted at Hospital Estadual Mário Covas, Faculdade de Medicina do ABC (FMABC), Santo André, SP, Brazil

Article received: $7 / 14 / 2015$ Accepted for publication: $7 / 27 / 2015$

*Correspondence: Address: Av. Príncipe de Gales, 821 anexo 3

Santo André, SP - Brazi Postal code: 09060-650 damilatrufelli@yahoo.com.br

http://dx.doi.org/10.1590/1806-9282.62.07.647

\section{SUMMARY}

Introduction: In patients with essential thrombocythemia (ET), the vascular complications contribute to morbidity and mortality. To better predict the occurrence of thrombotic events, an International Prognostic Score for Thrombosis in Essential Thrombocythemia (IPSET-thrombosis) has recently been proposed. We present the application of this score and compare its results with the usual classification system.

Method: We retrospectively evaluated the characteristics and risk factors for thrombosis of 46 patients with a diagnosis of ET seen in the last 6 years at Faculdade de Medicina do ABC (FMABC).

Results: Thrombosis in the arterial territory was more prevalent than in venous sites. We observed that cardiovascular risk factors (hypertension, hypercholesterolemia, diabetes mellitus, and smoking) were also risk factors for thrombosis $(\mathrm{p}<0.001)$. Age over 60 years and presence of JAK2 V617F mutation were not associated with the occurrence of thrombotic events. No patient classified by IPSET-thrombosis as low risk had a thrombotic event. Furthermore, using the IPSET-thrombosis scale, we identified two patients who had thrombotic events during follow-up and were otherwise classified in the low-risk group of the traditional classification. Leukocytosis at diagnosis was significantly associated with arterial thrombosis $(\mathrm{p}=0.02)$, while splenomegaly was associated with venous thrombotic events $(\mathrm{p}=0.01)$.

Conclusion: Cardiovascular risk factors and leukocytosis were directly associated with arterial thrombosis. IPSET-thrombosis appears to be better than the traditional classification at identifying lower risk patients who do not need specific therapy.

Keywords: essential thrombocythemia, thrombosis, prognosis.

\section{INTRODUCTION}

Essential thrombocythemia (ET) is a clonal disorder of the hematopoietic stem cells that is part of the chronic myeloproliferative neoplasms (cMPN). ${ }^{1} \mathrm{ET}$ diagnosis requires a sustained increase in platelet count $\left(\geq 450 \times 103 / \mathrm{mm}^{3}\right)$ and megakaryocytic hyperplasia. Furthermore, to diagnose ET, there should not be any clinical, pathological or molecular evidence to support the diagnosis of polycythemia vera, myelofibrosis, chronic myelogenous leukemia, myelodysplastic syndrome or reactive thrombocytosis. ${ }^{2}$ Among the
cMPN, ET is the most common and also has the most favorable clinical course. Survival is about 20 years in patients diagnosed with ET after 60 years of age, and approximately 33 years for younger individuals. ${ }^{3,4}$

Several authors identified molecular alterations in ET such as Janus Kinase 2 (JAK2) V617F mutation in 60\% of patients, mutations in the thrombopoietin receptor gene in $4 \%$, and mutations in the calreticulin gene in 15 to $32 \%$ of them. ${ }^{5-7}$ These findings relate to the pathogenesis of ET and are important to differentiate it from reactive throm- 
bocytosis. The absence of these molecular changes, however, does not exclude ET, since 15 to $20 \%$ of the patients can be triple negative. ${ }^{3,8}$ There is no relationship between mutational status and reduced survival in $\mathrm{ET} .^{3}$

The natural history of ET is characterized by the increase in vascular complications and potential risk of progression to acute myeloid leukemia in about $5 \%$, while transformation into myelofibrosis is a little more frequent. ${ }^{8}$ Since thrombotic events constitute the main complication of ET and because of its impact on survival, risk stratification for thrombosis is an essential part of the initial clinical evaluation of ET patients. In fact, being over the age of 60 years and having a history of previous thrombosis are two well-established risk factors for thrombosis in these patients. These two factors allowed to stratify ET subjects into a low- (without any of these two risk factors) or a high-risk category (presence of one or both factors). ${ }^{8-10}$ Based on this classification, clinical guidelines advise prescribing cytoreductive therapy for high-risk patients in order to avoid thrombotic complications. ${ }^{9,10}$

Recently, the International Prognostic Score for Thrombosis in Essential Thrombocythemia (IPSET-thrombosis) study ${ }^{10}$ examined the impact of new risk factors for ET risk-stratification. In fact, IPSET-thrombosis includes, in addition to age and previous history of thrombosis, the presence of JAK2 mutation and cardiovascular risk factors (hypercholesterolemia, hypertension, diabetes mellitus, and smoking).

In our study, we applied the IPSET-thrombosis and compared it with the risk stratification system traditionally used in patients with ET based on age and previous history of thrombotic events. Additionally, we sought to identify which risk factors were associated with thrombosis in this population.

\section{Method}

This study included 46 patients with a diagnosis of ET established according to the revised criteria of World Health Organization in 2008. We obtained patient information from electronic health records, which include all the clinical data from April 2008 onwards. Data was collected retrospectively, at a single public university institution, Hospital Estadual Mário Covas (HEMC), Faculdade de Medicina do ABC (FMABC).

We analyzed the following data: demographic characteristics (sex, age), clinical and laboratory data (complete blood count at diagnosis and JAK2 mutation), history of previous thrombosis, bleeding or thrombotic events during follow-up. In addition, we analyzed the presence of cardiovascular risk factors such as hyperten- sion, diabetes, current or recent smoking habit, and dyslipidemia. In this study, we considered as thrombotic events: acute myocardial infarction, ischemic stroke, deep vein thrombosis and arterial thrombosis if documented by imaging studies.

We stratified patients according to the traditional classification strata in two groups: low risk and high risk for thrombosis. In this classification, the presence of any one of the two criteria (age $\geq 60$ years or previous thrombosis) already defines the risk as high. We also classified patients according to the recent IPSET-thrombosis score that identifies three risk groups: low (0-1 points), intermediate (2 points), and high risk (3-4 points). IPSET-thrombosis considers the following variables: age (1 point), presence of cardiovascular risk factors (1 point), presence of JAK2 V617F mutation ( 2 points), and a history of thrombosis ( 2 points).

For statistical analysis, we evaluated associations between categorical variables using Chi-square or Fisher exact tests. In order to assess the presence of significant associations between qualitative and quantitative variables, we used t-Student test. All analyses were carried out with the aid of the SPSS ${ }^{\circledR}$ software version 17.0 (SPSS $₫$ Inc.; Illinois, USA). We considered significant p-values less than $0.05(\mathrm{p}<0.05)$.

\section{Results}

Between April 2008 and January 2015, we included 46 consecutive patients with a diagnosis of ET seen at HEMC. The median age at diagnosis was 61 years, with a female predominance. Microcirculatory symptoms were reported by approximately one-third of the patients, headache being the most frequent complaint. Fifteen (32.6\%) patients had splenomegaly at diagnosis; 24 (52.2\%) had hypertension; 5 (10.9\%) had diabetes; 17 (37\%) had dyslipidemia; and 8 (17.4\%) were smokers. The median white blood cells (WBC) and platelet counts were $9,375 / \mathrm{mm}^{3}$ and $753,000 / \mathrm{mm}^{3}$, respectively. Twenty patients $(43.5 \%)$ had WBC greater than $11,000 / \mathrm{mm}^{3}$ and 12 (26\%) had a platelet count greater than $1 \mathrm{million} / \mathrm{mm}^{3}$. We tested 42 patients (91.3\%) for JAK2 V617F mutation, of which 24 (57.1\%) were positive for this abnormality. Table 1 summarizes the clinical and laboratory data of the patients included at diagnosis.

According to the current risk classification, we classified 16 patients (34.8\%) as low risk and 30 as high risk for thrombosis at diagnosis (Table 2). Of the 19 patients who had thrombotic events, two had these events before the diagnosis of thrombosis, while 11 presented these events concomitant to the diagnosis of ET, and six had thrombotic events during follow-up. 
TABLE 1 Clinical and laboratory characteristics.

\begin{tabular}{ll} 
Variables & $\mathbf{n}(\mathbf{\%})$ \\
\hline Female & $31(67.4)$ \\
\hline Age at diagnosis - years, median (range) & $61(16-85)$ \\
\hline$\geq 60$ years & $23(50)$ \\
\hline JAK2, $\mathrm{n}=42$ & $24(57.1)$ \\
\hline Hemoglobin at diagnosis $-\mathrm{g} / \mathrm{dL}$, median $($ range $)$ & $14.0(7.2-18.4)$ \\
\hline White blood cells count at diagnosis $-\mathrm{x} 103 / \mathrm{mm}^{3}$, & $9.375(2.04-27.36)$ \\
median (range) & \\
\hline Platelets at diagnosis $-\mathrm{x} 103 / \mathrm{mm}^{3}$, median $(\mathrm{range})$ & $753(327-1800)$ \\
\hline White blood cells count $\geq 11 \times 103 / \mathrm{mm}^{3}$ & $20(43.5)$ \\
\hline Platelets $\geq 1,000 \times 103 / \mathrm{mm}^{3}$ & $12(26)$ \\
\hline Splenomegaly & $15(32.6)$ \\
\hline Thrombosis & $19(41.3)$ \\
\hline Venous thrombosis, $\mathrm{n}=19$ & $6(31.6)$ \\
\hline Arterial thrombosis, $\mathrm{n}=19$ & $13(68.4)$ \\
\hline Bleeding & $10(21.7)$ \\
\hline $\mathrm{n}:$ number of patients. &
\end{tabular}

\section{TABLE 2 Risk stratification at diagnosis.}

\begin{tabular}{ll} 
Variables & $\mathbf{n}(\%)$ \\
\hline \multicolumn{2}{l}{ Risk stratification - usual classification system, $\mathbf{N}=\mathbf{4 6}$} \\
\hline Low risk & $16(34.8)$ \\
\hline High risk & $30(65.2)$ \\
\hline \multicolumn{2}{l}{ Risk stratification - IPSET-thrombosis, $\mathbf{n = 4 4 ^ { \# }}$} \\
\hline Low risk & $12(27.3)$ \\
\hline Intermediate risk & $8(18.2)$ \\
\hline High risk & $24(54.5)$ \\
\hline n: number of patients; "absence of JAK2 mutation data.
\end{tabular}

Thirteen patients (68.4\%) presented arterial thrombosis and six $(31.6 \%)$ had venous thrombosis. Of the patients who experienced thrombotic events, two belonged to the low-risk category and 17 to the high-risk, by the classical risk classification (Table 3). Of the 17 patients classified as high risk for thrombosis, 14 (82.3\%) were using cytoreductive therapy with hydroxyurea. Applying IPSET-thrombosis, we observed that the low-risk category consisted of only 12 patients; the high-risk group had 24 patients, while eight patients had intermediate risk (Table 2). Two patients, however, could not be classified by IPSET-thrombosis because of the absence of data regarding JAK2 mutations, and both belonged to the high-risk group by the previous classification due to age above 60 years. Of the four patients who were no longer considered low risk, when we applied the IPSET-thrombosis score, two were allocated to the IPSET-thrombosis high-risk category and two to the intermediate-risk category. Interestingly, the two patients reclassified as highrisk by IPSET-thrombosis developed thrombosis during follow-up. Furthermore, considering the parameters of IPSET-thrombosis, no low-risk patient had any thrombotic event during the follow-up period. We observed only one patient categorized as intermediate risk with a thrombotic event detected prior to ET diagnosis, while $18(75 \%)$ of the high-risk category patients had thrombotic complication during follow-up (Table 3).

\begin{tabular}{|c|c|c|c|}
\hline Variables & $\begin{array}{l}\text { Thrombosis } \\
(n=19)\end{array}$ & $\begin{array}{l}\text { No thrombosis } \\
(n=27)\end{array}$ & $\mathbf{P}$ \\
\hline \multicolumn{4}{|c|}{ Risk stratification - usual classification system } \\
\hline Low risk & $2(10.5 \%)$ & $14(51.9 \%)$ & \multirow[t]{2}{*}{0.04} \\
\hline High risk & $17(89.5 \%)$ & $13(48.1 \%)$ & \\
\hline \multicolumn{4}{|c|}{ Risk stratification - IPSET-thrombosis, $n=44^{\#}$} \\
\hline Low risk & 0 & $12(48 \%)$ & \multirow[t]{3}{*}{$<0.001$} \\
\hline Intermediate risk & $1(5.3 \%)$ & $7(28 \%)$ & \\
\hline High risk & $18(94.7 \%)$ & $6(24 \%)$ & \\
\hline
\end{tabular}

While evaluating in our population the risk factors that could correlate with thrombosis, we observed that patients with a thrombotic event in the venous territory had significantly more instances of splenomegaly $(\mathrm{p}=0.01)$. In relation to arterial thrombosis, risk factors identified were the presence of a cardiovascular risk factor $(\mathrm{p}<0.001)$ and high WBC at diagnosis ( $\mathrm{p}=0.02)$.

Age over 60 years and the presence of JAK2 mutation were not significantly associated with arterial or venous thrombotic phenomena in our study sample (Table 4).

\section{Discussion}

Indication of therapy in patients with ET depends on their thrombotic risk. ${ }^{11-13}$ Therefore, prognostic systems to classify patients into risk categories are critical because they should receive myelosuppressive therapy if classified as high risk. However, if patients are deemed as having low risk for thrombosis, myelosuppressive therapy can be avoided. Therefore, attempts to improve current risk estimation algorithms include additional variables with potential prognostic impact such as the presence of JAK2 mutation and cardiovascular risk factors. ${ }^{1,10}$ As a result, a new model was recently proposed and called IPSET-thrombosis score. ${ }^{10}$ 
TABLE 4 Association between thrombosis and clinical and laboratory parameters.

\begin{tabular}{|c|c|c|c|c|c|c|}
\hline Variables & $\begin{array}{l}\text { Thrombosis } \\
(n=19)\end{array}$ & $\mathbf{p}$ & $\begin{array}{l}\text { Venous } \\
\text { thrombosis }(n=6)\end{array}$ & $\mathbf{p}$ & $\begin{array}{l}\text { Arterial } \\
\text { thrombosis }(n=13)\end{array}$ & $\mathbf{p}$ \\
\hline$\geq 60$ years & $11(57.9 \%)$ & 0.2 & $4(66.7 \%)$ & 0.5 & $7(53.8 \%)$ & 0.9 \\
\hline $\mathrm{JAK} 2, \mathrm{n}=42$ & $11(64.7 \%)$ & 0.4 & $4(66.7 \%)$ & 0.6 & $7(63.3 \%)$ & 0.3 \\
\hline WBC at diagnosis $/ \mathrm{mm}^{3}$, median & 12,325 & 0.04 & 9,165 & 0.4 & 13,300 & 0.02 \\
\hline Splenomegaly & $9(47.4 \%)$ & 0.07 & $5(83.3 \%)$ & 0.004 & $4(30.7 \%)$ & 0.8 \\
\hline Cardiovascular risk factors ${ }^{\#}$ & $17(89.5 \%)$ & 0.01 & $5(83.3 \%)$ & 0.4 & $12(92.3 \%)$ & 0.03 \\
\hline
\end{tabular}

n: number of patients; WBC: white blood cells; "tobacco use, arterial hypertension, diabetes and hypercholesterolemia (at least one).

In our population, according to the current risk stratifying protocol based solely on age and previous history of thrombosis, 16 patients belonged to the low-risk and 30 to the high-risk group. Applying the IPSET-thrombosis score, we observed a decrease in size of the low-risk group, since two patients were allocated to the intermediate and two to the high-risk group. The two patients who were categorized as high risk by IPSET-thrombosis were not receiving cytoreductive therapy and developed thrombosis during follow-up. Possibly, if we had employed IPSET-thrombosis classification initially, these two patients would have received cytoreductive therapy and perhaps would not have had thrombotic manifestations. It is important to stress that none of the patients considered low-risk based on the IPSET-thrombosis classification had any thrombotic event during our study.

In relation to the high-risk group of the traditional classification containing 30 patients, in only 28 we were able to apply the IPSET-thrombosis score. Twenty-four patients remained in the high-risk category of the IPSET-thrombosis criteria. Of the four patients who were removed from the high-risk group, three were allocated into the low-risk category and one into the intermediate-risk according to IPSET-thrombosis criteria. All these patients were receiving cytoreductive therapy, and none of them presented clinical thrombosis during follow-up. Therefore, we could have spared perhaps two patients from cytoreductive therapy. Furthermore, in our study, the application of IPSET-thrombosis would have changed the risk classification in six (13.6\%) and the management of at least four (9.5\%) patients. Our results agree with those of Barbui et al., ${ }^{10}$ who also showed that IPSET-thrombosis outperform the traditional risk stratification system.

So far, the indication of treatment for ET is guided by the guidelines of the LeukemiaNet, ${ }^{14}$ which is based on the traditional risk stratification. ${ }^{15}$ In the future, however, some authors already believe that the IPSET-thrombosis classification will be incorporated to stratify patients with ET. ${ }^{8,9,16}$
The demographic characteristics, clinical and laboratory parameters of our sample of patients are similar to those described in the literature. ${ }^{3}$ Hemorrhagic events were less prevalent than the thrombotic ones also in agreement with previous studies. ${ }^{17-19}$ Additionally, in agreement with other authors, we found a significant association between splenomegaly and venous thrombosis, and cardiovascular risk factors and a high WBC with arterial thrombosis. ${ }^{17,8,10,16}$

Interestingly, age $\geq 60$ years in our cohort of patients was not a significant risk factor for thrombosis. The lack of correlation between older age and thrombosis was also seen in other recent studies such as those of Lekovic et al. ${ }^{1}$ and Montanaro et al. ${ }^{20}$ The presence of JAK2 mutation was not significantly associated with thrombosis in our study, contrary to information well-established in the literature. ${ }^{14,16,20-22}$ We believe that our small sample size may explain why we found no correlation between thrombosis risk and the presence of JAK2 mutation.

Our study has limitations. It is retrospective and included a small sample of ET patients who had a relatively short follow-up. However, even considering the shortcomings mentioned above, we could clearly see that the risk classification afforded by IPSET-thrombosis could improve the therapeutic management of ET in about 10\% of patients.

\section{Resumo}

Aplicação do escore prognóstico IPSET-trombose nos pacientes com trombocitemia essencial em um hospital público brasileiro

Introdução: em pacientes com trombocitemia essencial (TE), complicações vasculares contribuem para morbidade e mortalidade. Para melhor predizer a ocorrência de eventos trombóticos, um escore prognóstico internacional de trombose para TE (IPSET-trombose) foi recentemente desenvolvido. Apresentamos aqui a aplicação des- 
se escore e comparamos seus resultados com o sistema de classificação usual.

Método: avaliamos retrospectivamente as características e os fatores de risco para trombose em 46 pacientes com diagnóstico de TE que foram atendidos nos últimos 6 anos na Faculdade de Medicina do ABC.

Resultados: trombose em território arterial é mais prevalente que em sítio venoso. Observamos que fatores de risco cardiovascular (hipertensão, hipercolesterolemia, diabetes mellitus e tabagismo) foram considerados fatores de risco para trombose $(\mathrm{p}<0,001)$. Idade $>60$ anos e presença de mutação JAK2 V617F não se associaram à ocorrência de eventos trombóticos. Nenhum paciente classificado como baixo risco pelo IPSET-trombose apresentou evento trombótico. Quando comparado à classificação de risco tradicional, IPSET-trombose foi capaz de identificar dois pacientes que evoluíram com trombose no seguimento e estavam categorizados no grupo de baixo risco. Leucocitose ao diagnóstico foi mais prevalente em pacientes que apresentaram trombose arterial $(\mathrm{p}=0,02)$, e esplenomegalia, entre aqueles com evento trombótico venoso $(p=0,01)$.

Conclusão: fatores de risco cardiovascular e leucocitose se associaram de forma direta com trombose arterial. IPSET-trombose parece ser melhor que a classificação tradicional na identificação de pacientes de baixo risco que não precisam de terapia específica.

Palavras-chave: trombocitemia essencial, trombose, prognóstico.

\section{RefEREnCES}

1. Lekovic D, Gotic M, Milic N, Miljic P, Mitrovic M, Cokic V, et al. The importance of cardiovascular risk factors for thrombosis prediction in patients with essential thrombocythemia. Med Oncol. 2014; 31(10):231.

2. Vardiman JW, Thiele J, Arber DA, Brunning RD, Borowitz MJ, Porwit A, et al. The 2008 revision of the World Health Organization (WHO) classification of myeloid neoplasms and acute leukemia: rationale and important changes. Blood. 2009; 114(5):937-51.

3. Tefferi A, Guglielmelli P, Larson D, Finke C, Wassie EA, Pieri L, et al. Longterm survival and blast transformation in molecularly annotated essential thrombocythemia, polycythemia vera, and myelofibrosis. Blood. 2014; 124(16):2507-13

4. Wolanskyj AP, Schwager SM, McClure RF, Larson DR, Tefferi A. Essential thrombocythemia beyond the first decade: life expectancy, long-term complication rates, and prognostic factors. Mayo Clin Proc. 2006; 81(2):159-66.

5. Levine R. Another piece of the myeloproliferative neoplasms puzzle. N Engl J Med. 2013; 369(25):2451-2.
6. Tefferi A, Vainchenker W. Myeloproliferative neoplasms: molecular pathophysiology, essential clinical understanding, and treatment strategies. J Clin Oncol. 2011; 29(5):573-82.

7. Rumi E, Pietra D, Ferretti V, Klampfl T, Harutyunyan AS, Milosevic JD, et al.; Associazione Italiana per la Ricerca sul Cancro Gruppo Italiano Malattie Mieloproliferative Investigators. JAK2 or CALR mutation status defines subtypes of essential thrombocythemia with substantially different clinical course and outcomes. Blood. 2014; 123(10):1544-51.

8. Barosi G, Tefferi A, Besses C, Birgegard G, Cervantes F, Finazzi G, et al Clinical end points for drug treatment trials in BCR-ABL1 negative classic myeloproliferative neoplasms: consensus statements from European LeukemiaNET (ELN) and International Working Group-Myeloproliferative Neoplasms Research and Treatment (IWG-MRT). Leukemia. 2015; 29(1):20-6

9. Karali V, Panayiotidis P. Novel oral anticoagulants in the management of polycythemia vera and essential thrombocythemia. Cardiovasc Hematol Agents Med Chem. 2014; 12(1):26-8.

10. Barbui T, Finazzi G, Carobbio A, Thiele J, Passamonti F, Rumi E, et al. Development and validation of an International Prognostic Score of thrombosis in World Health Organization-essential thrombocythemia (IPSET-thrombosis). Blood. 2012; 120(26):5128-33.

11. Hernández-Boluda JC, Gómez M. Target hematologic values in the management of essential thrombocythemia and polycythemia vera. Eur J Haematol. 2015; 94(1):4-11.

12. Tefferi A, Barbui T. Personalized management of essential thrombocythemia - application of recent evidence to clinical practice. Leukemia. 2013; 27(8):1617-20.

13. Tefferi A, Vainchenker W. Myeloproliferative neoplasms: molecular pathophysiology, essential clinical understanding, and treatment strategies. J Clin Oncol. 2011; 29(5):573-82.

14. Barbui T, Barosi G, Birgegard G, Cervantes F, Finazzi G, Griesshammer M, et al.; European LeukemiaNet. Philadelphia-negative classical myeloproliferative neoplasms: critical concepts and management recommendations from European LeukemiaNet. J Clin Oncol. 2011; 29(6):761-70.

15. Tefferi A. Polycythemia vera and essential thrombocythemia: 2012 update on diagnosis, risk stratification, and management. Am J Hematol. 2012; 87(3):285-93.

16. Fu R, Xuan M, Lv C, Zhang L, Li H, Zhang X, et al. External validation and clinical evaluation of the International Prognostic Score of Thrombosis for Essential Thrombocythemia (IPSET-thrombosis) in a large cohort of Chinese patients. Eur J Haematol. 2014; 92(6):502-9.

17. Borowczyk M, Wojtaszewska M, Lewandowski K, Gil L, Lewandowska M, Lehmann-Kopydłowska A, et al. The JAK2 V617F mutational status and allele burden may be related with the risk of venous thromboembolic events in patients with Philadelphia-negative myeloproliferative neoplasms. Thromb Res. 2015; 135(2):272-80.

18. Gisslinger H, Gotic M, Holowiecki J, Penka M, Thiele J, Kvasnicka HM, et al.; ANAHYDRET Study Group. Anagrelide compared with hydroxyurea in WHO-classified essential thrombocythemia: the ANAHYDRET Study, a randomized controlled trial. Blood. 2013; 121(10):1720-8.

19. Carobbio A, Thiele J, Passamonti F, Rumi E, Ruggeri M, Rodeghiero F, et al. Risk factors for arterial and venous thrombosis in WHO-defined essential thrombocythemia: an international study of 891 patients. Blood. 2011; 117(22):5857-9.

20. Montanaro M, Latagliata R, Cedrone M, Spadea A, Rago A, Di Giandomenico $\mathrm{J}$, et al. Thrombosis and survival in essential thrombocythemia: a regional study of 1,144 patients. Am J Hematol. 2014; 89(5):542-6.

21. Takata Y, Seki R, Kanajii T, Nohara M, Koteda S, Kawaguchi K, et al. Association between thromboembolic events and the JAK2 V617F mutation in myeloproliferative neoplasms. Kurume Med J. 2014; 60(3-4):89-97.

22. Passamonti F. Prognostic factors and models in polycythemia vera, essential thrombocythemia, and primary myelofibrosis. Clin Lymphoma Myeloma Leuk. 2011; 11(Suppl 1):S25-7. 